The study population comes from San Bernardino, Fresno, and Tulare counties, all counties within the top 10 for reported elevated blood lead levels in children. In addition, Sonoma County was also sampled since it is in the top third of California counties with houses built prior to 1950 .

Using a Food Frequency Questionnaire and three 24-hour dietary recalls, along with blood tests, Zidenberg-Cherr hopes to determine whether diets low in such nutrients as calcium, iron and zinc increase a child's susceptibility to lead toxicity.

The pilot project is also designed to test how well their methods work in getting dietary information about children. Among other things, parents are asked to recount what their children typically eat and the size of their portions. "With kids that's really hard," she said.

Zidenberg-Cherr said this study is designed to determine whether a relationship exists between certain nutrients and blood lead levels. She hopes to conduct a second study, using the results from the current study to determine whether supplemental diets might be used as a means to reduce lead toxicity in children.

The California Department of Health has estimated that some 80,000 children have blood lead levels above $15 \mathrm{ug} / \mathrm{dl}$. Children with extremely high blood lead levels are treated with drugs called "chelators" which have the ability to bind to lead and remove it from the body. Cost of such treatment is dependent on severity, and ranges from about $\$ 200$ to $\$ 5,000$, Zidenberg-Cherr said.

Some have argued for universal screening, which would cost about $\$ 25$ per child, she said. Reaction among health care professionals is mixed in part because of the cost, and because no therapy is available for children with slightly elevated blood lead levels, beyond simply removing the sources of lead and educating parents. - Editor
Chronic exposure to lead can lead to serious health and behavioral problems such as anemia, kidney disease, lower $1 Q$...

\title{
UC offers lead test around state
}

Fom or the past few years, UC Cooperative Extension offices around the state have been offering what they call the "UC Quick Lead Test," a 20-minute test which can determine whether a piece of pottery or ceramic ware is leaching lead.

Many pottery glazes contain lead, which adds color, texture and luster. When properly fired or heated to a high enough temperature for a long enough time - the metals become incorporated into the glaze and are resistant to acid leaching.

But some pottery isn't properly prepared or fired. Glazes that are cracked or worn can also cause leaching of lead when they come into contact with acidic foods, such as tomatoes, according to UC Home Economist Shirley Peterson.

In 1991, concerned about the health effects of lead, the U.S. Food and Drug Administration (FDA) issued new guidelines concerning pottery and ceramics manufactured in, or imported to, the United States. Pottery made in the United States, or foreign pottery imported through FDA-approved channels, are screened for leachable lead. Not all pottery or ceramics manufactured in foreign countries meet FDA standards. Tourists and military may bring home dishware from foreign countries, which are not subjected to the screening process, but may contain leachable lead. Lead can also be found in antiques.

The UC lead test, which is adapted from an FDA test, uses a mixture of citric acid, "about as strong as lemonade," which is placed on all colors in the pottery that come into contact with food, Peterson said. After standing for 20 minutes, some of this citric acid is transferred to filter paper, where it is tested with rhodizonic acid, which turns from goldenrod to pink on contact with lead. The darker the pink, the more lead is there.

Cooperative Extension originally offered the test at a Davis farmers' market and the Sacramento County Extension Office. Of 92 pieces tested, they found more than $6 \%$ leached lead, many of them pieces from Mexico, in which the glaze had been poorly or incompletely applied, and the pieces gave a "thunk" when tapped, which is indicative of ceramic ware fired at a low temperature.

Peterson said the lead tests are available at many of the Cooperative Extension offices. In addition, they can be obtained commercially for people who are concerned about the safety of their ceramic ware. - Editor
UC's 20-minute lead test uses citric acid to determine the presence of leachable lead in pottery. 